\title{
Postsynaptic Depolarization Scales Quantal Amplitude in Cortical Pyramidal Neurons
}

\author{
Kenneth R. Leslie, Sacha B. Nelson, and Gina G. Turrigiano \\ Department of Biology and Center for Complex Systems, Brandeis University, Waltham, Massachusetts 02454
}

Pyramidal neurons scale the strength of all of their excitatory synapses up or down in response to long-term changes in activity, and in the direction needed to stabilize firing rates. This form of homeostatic plasticity is likely to play an important role in stabilizing firing rates during learning and developmental plasticity, but the signals that translate a change in activity into global changes in synaptic strength are poorly understood. Some but not all of the effects of long-lasting changes in activity on synaptic strengths can be accounted for by activitydependent release of the neurotrophin brain-derived neurotrophic factor (BDNF). Other candidate activity signals include changes in glutamate receptor (GluR) activation, changes in firing rate, or changes in the average level of postsynaptic depolarization. Here we combined elevated $\mathrm{KCl}(3-12 \mathrm{~mm})$ with

Neurons use a variety of homeostatic mechanisms to counter the destabilizing effects of plasticity and keep firing rates within functional boundaries (Turrigiano, 1999). One of these mechanisms is synaptic scaling: pyramidal neurons are able to upregulate or downregulate the quantal amplitude of all of their excitatory synapses in an activity-dependent manner, and in the direction needed to maintain stability (Turrigiano et al., 1998). Because this process scales synapses proportionally, it preserves the relative differences in strength between different synaptic inputs. Synaptic scaling has a slow time course (24-48 hr) and is at least partially mediated by changes in the number of postsynaptic glutamate receptors (GluRs) (O’Brien et al., 1998; Turrigiano et al., 1998; Watt et al., 2000).

For synaptic scaling to work, neurons need to integrate some measure of activity over a long time scale and transduce this measurement into a signal that modifies quantal amplitude. Brain-derived neurotrophic factor (BDNF) appears to mediate some of the effects of activity on quantal amplitude (Rutherford et al., 1998). BDNF is released by pyramidal neurons in an activity-dependent manner (Castren et al., 1992; Balkowiec and Katz, 2000) and binds to TrkB receptors on both pyramidal and inhibitory interneurons (Kokaia et al., 1993; Miranda et al., 1993). $\mathrm{BDNF}$ is especially important for the activity-dependent regulation of inhibitory circuits: high concentrations of BDNF lead to

\footnotetext{
Received April 4, 2001; revised June 22, 2001; accepted July 17, 2001.

This work was supported by National Institutes of Health Grant RO1 NS36853 and by National Science Foundation Grant IBN 9726944. G.G.T. was supported by Career Development Award K02 NS01893 from the National Institute of Neurological Disorders and Stroke. K.R.L. was supported by a Howard Hughes Medical Institute Predoctoral Fellowship.

Correspondence should be addressed to Dr. Gina Turrigiano, Department of Biology and Center for Complex Systems, MS008, Brandeis University, Waltham, MA 02454. E-mail: turrigiano@brandeis.edu.

Copyright (ㄷ) 2001 Society for Neuroscience $\quad 0270-6474 / 01 / 210001-06 \$ 15.00 / 0$
}

ionotropic receptor blockade to dissociate postsynaptic depolarization from receptor activation. Chronic (48 hr) depolarization, ranging between -62 and $-36 \mathrm{mV}$, parametrically reduced the quantal amplitude of excitatory synapses in a BDNFindependent manner. This effect of depolarization did not

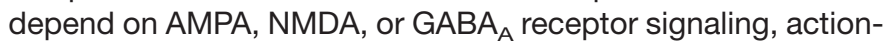
potential generation, or metabotropic GluR activation. Together with previous work, these data suggest that there are two independent signals that regulate activity-dependent synaptic scaling in pyramidal neurons: low levels of BDNF cause excitatory synapses to scale up in strength, whereas depolarization causes excitatory synapses to scale down in strength.

Key words: BDNF; synaptic scaling; activity-dependent; synaptic plasticity; KCl; depolarization; MEPSC

increased inhibition in a variety of preparations (Isackson et al., 1991; Zafra et al., 1991; Castren et al., 1992; Ghosh et al., 1994; Rutherford et al., 1997; Vicario-Abejon et al., 1998; Huang et al., 1999; Marty et al., 2000; Seil and Drake-Baumann, 2000) and also increase the amplitude of miniature EPSCs (mEPSCs) onto inhibitory interneurons (Rutherford et al., 1998).

Although BDNF has important effects on quantal amplitude and neuronal excitability (Rutherford et al., 1998; Desai et al., 1999), changes in BDNF alone cannot account for the bidirectional regulation of quantal amplitude by long-lasting changes in activity. Lowering activity increases mEPSC amplitude by reducing the release of endogenous BDNF (Rutherford et al., 1998). However, adding exogenous BDNF does not reduce mEPSC amplitudes below control values, suggesting that increased activity does not scale down mEPSC amplitude by increasing the release of BDNF. Thus, although activity can bidirectionally scale mEPSC amplitude, BDNF can only account for part of this regulation. This raises the question of what signal transduces high levels of activity into a reduction in mEPSC amplitude. Possible signals include changes in firing rate, changes in glutamate receptor activation (Lissin et al., 1998; O'Brien et al., 1998), and

This article is published in The Journal of Neuroscience, Rapid Communications Section, which publishes brief, peerreviewed papers online, not in print. Rapid Communications are posted online approximately one month earlier than they would appear if printed. They are listed in the Table of Contents of the next open issue of JNeurosci. Cite this article as: JNeurosci, 2001, 21:RC170 (1-6). The publication date is the date of posting online at www.jneurosci.org.

http://www.jneurosci.org/cgi/content/full/5671 


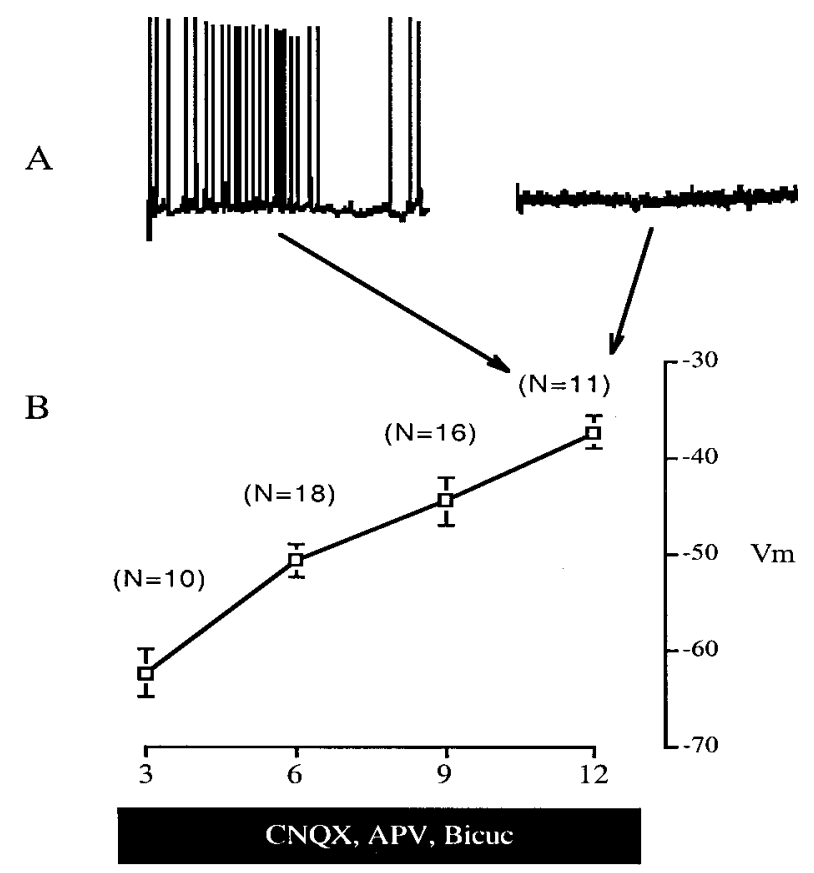

$\mathrm{KCl}$ in $\mathrm{mM}$

Figure 1. Average membrane potential of neurons in different external $\mathrm{KCl}$ concentrations. $A$, Representative recordings from two different neurons in $12 \mathrm{~mm} \mathrm{KCl}$ in synaptic blockade (CNQX, APV, bicuculline). Some neurons spontaneously fire while some inactivate. $B$, All neurons depolarize with increased extracellular $\mathrm{KCl}$ in synaptic blockade. In this and subsequent figures, the black bar indicates that cultures were grown for $2 \mathrm{~d}$ in the presence of the indicated pharmacological agents.

changes in the average level of postsynaptic depolarization. We used elevated external $\mathrm{KCl}(3-12 \mathrm{~mm}$ ) in ionotropic receptor blockade to dissociate the effects of postsynaptic depolarization from glutamate receptor activation. Chronic depolarization parametrically reduced mEPSC amplitudes in the absence of AMPAkainate, NMDA, and $\mathrm{GABA}_{\mathrm{A}}$ receptor activation. The effects of depolarization were independent of action-potential generation and BDNF signaling. Together with previous results, these findings suggest that BDNF and postsynaptic membrane potential cooperate to regulate synaptic strength over the entire dynamic range of mEPSC amplitudes.

\section{MATERIALS AND METHODS}

Dissociated cultures were prepared as described previously (Rutherford et al., 1997; Desai et al., 1999; Watt et al., 2000) from postnatal day 3-5 rat pups and plated onto pre-existing astrocyte feeder layers. Whole-cell recordings were obtained in artificial CSF (ACSF) after 7-10 d in vitro. To extend the range of potassium concentrations used, the cultures used to test the parametric effect of external potassium were grown in medium containing only $3 \mathrm{~mm} \mathrm{KCl}$. All other experiments used cultures grown in standard 5.4 mM KCl medium. AMPA-mediated mEPSCs were recorded and analyzed as described previously (Rutherford et al., 1998; Turrigiano et al., 1998; Watt et al., 2000). For each experiment, data were collected from sister cultures grown under several experimental conditions; three to five conditions were collected per experiment. Results were then averaged across experiments for each of the conditions reported. All statistical tests were unmatched Student's $t$ tests, unless otherwise noted.

Both whole-cell and perforated patch recordings were used to measure acute resting membrane potentials at different external potassium concentrations in synaptic blockade (Fig. 1). The perforated patch technique allowed assessment of firing rate and membrane potential in the absence of cell dialysis. Similar results were obtained with both techniques, and both sets of data were combined for the final analysis. The perforated

patch internal solution contained (in $\mathrm{mM}$ ): $136.5 \mathrm{~K}$-gluconate, $17.5 \mathrm{KCl}$, $9 \mathrm{NaCl}, 1 \mathrm{MgCl}_{2}, 10 \mathrm{~K}$-HEPES, and 0.2 EGTA; the $\mathrm{pH}$ was adjusted to 7.4 with KOH. Amphotericin B (ICN Biomedicals Inc., Aurora, OH) was used as a perforating agent and was prepared as a stock solution in DMSO ( $1 \mathrm{mg}$ of amphotericin B in $20 \mu \mathrm{l}$ of DMSO; Sigma, St. Louis, MO) and stored as $2 \mu \mathrm{l}$ aliquots at $-20^{\circ} \mathrm{C}$ (Rae et al., 1991). Right before use, the aliquot was thawed and mixed with $400 \mu$ l of internal solution.

Chronic ionotropic receptor blockade was achieved by treating cultures with a cocktail of receptor blockers, namely, 6-cyano-7-nitroquinoxaline2,3-diome (CNQX) (Sigma) $(40 \mu \mathrm{M})$ to block AMPA and kainate receptors, D-(-)-2-amino-5-phosphono pentanoic acid (D-APV) (Sigma) (50$100 \mu \mathrm{M})$ to block NMDA receptors, and bicuculline (Sigma) $(10 \mu \mathrm{M})$ to block $\mathrm{GABA}_{\mathrm{A}}$ receptors. All blockers were refreshed after $24 \mathrm{hr}$. To chronically depolarize neurons, the external $\mathrm{KCl}$ concentration was elevated from either 3 or $5.4 \mathrm{~mm}$ (control conditions) to 6,9 , and $12 \mathrm{~mm}$.

When testing the acute effects of bicuculline and bicuculline plus D-APV on firing rate, the ACSF was adjusted to have a concentration of salts identical to regular minimal essential medium (Life Technologies, Rockville, MD) (in mM): $5.4 \mathrm{KCl}, 1 \mathrm{MgSO}_{4}$, and $1.8 \mathrm{CaCl}_{2}$. Cells were recorded at $35^{\circ} \mathrm{C}$ under three different conditions: control conditions with regular ACSF, bicuculline $(20 \mu \mathrm{M})$, and bicuculline $(20 \mu \mathrm{M})$ plus D-APV $(100 \mu \mathrm{M})$. TrkB-IgG was a gift from Genentech (South San Francisco, CA). Aliquots of TrkB-IgG were stored at $-80^{\circ} \mathrm{C}$ and thawed just before use. TrkB-IgG was used at a concentration of 2 or $10 \mu \mathrm{g} / \mathrm{ml}$. LY341495 $(100 \mu \mathrm{M})$ (Tocris, Ballwin, MO) was used as a general metabotropic GluR (mGluR) antagonist. LY341495 was mixed as a $10 \mathrm{~mm}$ stock in sterile water with $15 \mathrm{~mm} \mathrm{NaOH}$. In addition to $12 \mathrm{~mm} \mathrm{KCl}$ and ionotropic blockade, cultures were treated with LY341495 or a control NaOH stock. The treatment was refreshed after $24 \mathrm{hr}$. The low concentration of $\mathrm{NaOH}$ did not alter the $\mathrm{pH}$ of the medium, and there was no discernable change in neuronal health, whole-cell properties, mEPSC amplitude, rise time, or frequency. The $\mathrm{NaOH}$ controls were combined with other treated controls for the LY341495 experiment. Nifedipine (Sigma) $(5 \mu \mathrm{M})$ was used to block L-type voltage-gated calcium channels (VGCCs). Nifedipine was made up as a $5 \mathrm{~mm}$ stock in DMSO (Sigma). Control cultures were treated with DMSO alone $(0.1 \%)$. DMSO did not adversely affect neuronal properties or block scaling. The nifedipine was not refreshed.

\section{RESULTS}

\section{Chronic depolarization scales mEPSC amplitudes}

Previous reports have emphasized the importance of glutamate receptor activation for activity-dependent synaptic scaling (Lissin et al., 1998; O’Brien et al., 1998). To test this hypothesis while controlling for activity, we chronically depolarized cells with a range of $\mathrm{KCl}$ concentrations (3-12 $\mathrm{mm}$ ) while blocking ionotropic glutamate and $\mathrm{GABA}_{\mathrm{A}}$ receptors with CNQX $(40 \mu \mathrm{M})$, APV (50 $\mu \mathrm{M})$, and bicuculline $(10 \mu \mathrm{M})$ (henceforth referred to as ionotropic receptor blockade). This allowed us to dissociate receptor signaling from postsynaptic depolarization. Acute whole-cell current-clamp recordings showed that varying the potassium concentration in ionotropic receptor blockade depolarized pyramidal neurons from $-62 \pm 2.6 \mathrm{mV}$ (in $3 \mathrm{mM} \mathrm{KCl}$ ) to $-51 \pm 1.7 \mathrm{mV}(6$ $\mathrm{mm}),-45 \pm 2.5 \mathrm{mV}(9 \mathrm{~mm})$, and $-36 \pm 0.8 \mathrm{mV}(12 \mathrm{~mm})$ (Fig. $1 B)$. Note that some neurons at the higher potassium concentrations stopped firing, presumably because of sodium channel inactivation (Fig. $1 A$ ). Under ionotropic receptor blockade, the $\mathrm{KCl}$ concentration normally found in the medium $(5.4 \mathrm{~mm})$ yields cells that are still quite depolarized (i.e., interpolating from Figure 1 yields a value of approximately $-55 \mathrm{mV}$ ). To get a larger range of membrane potentials, neurons were grown in $3 \mathrm{~mm} \mathrm{KCl}$ medium. Control cultures raised in low potassium (3 $\mathrm{mm})$ had larger mEPSCs $(-19.7 \pm 2.5 \mathrm{pA})$ (Fig. 2) than control cultures raised in regular medium $(-13.6 \pm 0.7 \mathrm{pA}$; data not shown), indicating that reduced depolarization, which is likely to reduce ongoing activity, produced an increase in quantal amplitude.

After $48 \mathrm{hr}$ of treatment with different concentrations of $\mathrm{KCl}$ in the presence of ionotropic receptor blockers, cultures were perfused with regular ACSF in the presence of TTX (0.1 $\mu \mathrm{M})$, APV 
A
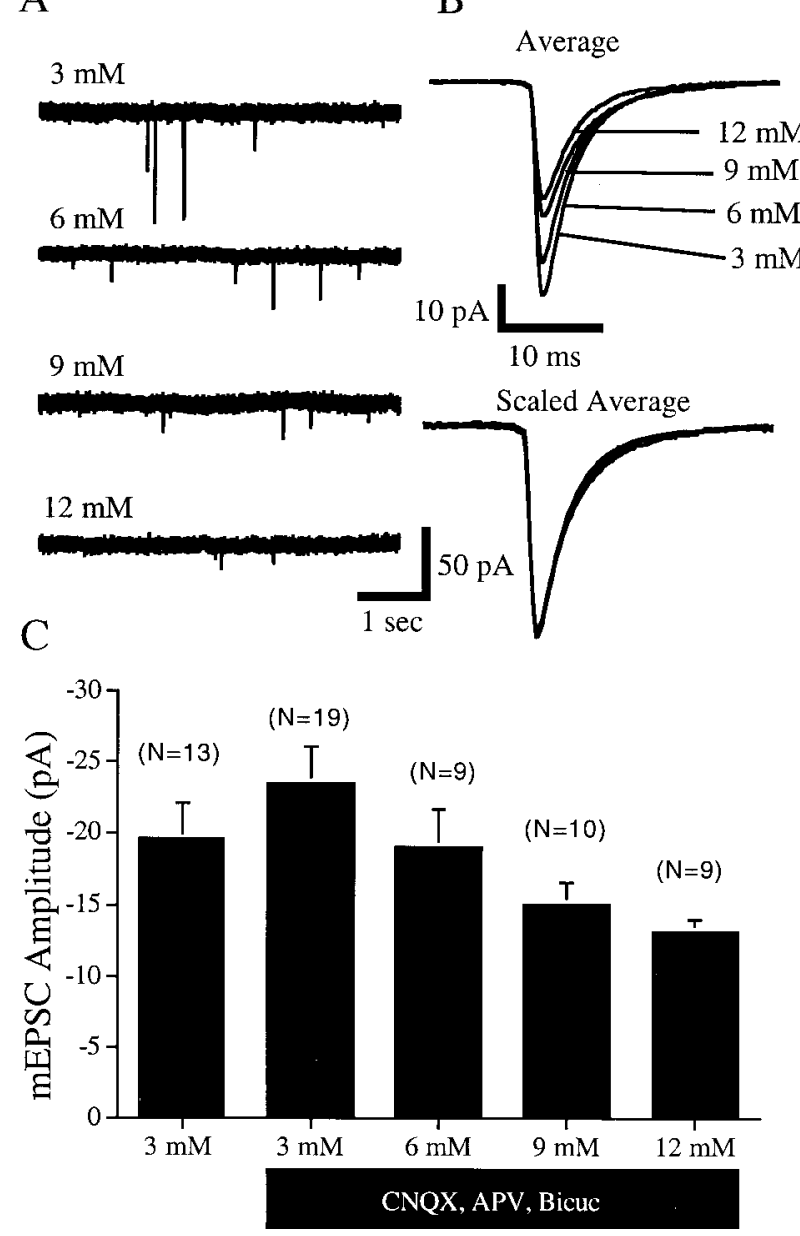

Figure 2. Depolarization parametrically reduces mEPSC amplitude. $A$, Representative mEPSC recordings from neurons treated for $2 \mathrm{~d}$ with synaptic blockade (CNQX, APV, bicuculline) and concentrations of $\mathrm{KCl}$ ranging between 3 and $12 \mathrm{~mm}$. $B$, Average mEPSC waveforms for each condition (Average). To compare kinetics, the average mEPSCs for the different $\mathrm{KCl}$ concentrations were scaled to the peak current and overlaid. The kinetics were not altered by treatment with different levels of external $\mathrm{KCl}$ (Scaled Average). C, Average mEPSC amplitude for neurons grown under the indicated conditions. mEPSC amplitude varied significantly as a function of the level of chronic depolarization ( $p \leq 0.015$; one-way ANOVA).

(100 $\mu \mathrm{M})$, and bicuculline $(20 \mu \mathrm{M})$. AMPA-mediated mEPSCs were then recorded from visually identified pyramidal neurons. Quantal amplitude was significantly decreased by elevated $\mathrm{KCl}$ ( $p \leq 0.015$; single-factor ANOVA), from $-23.5 \pm 2.6 \mathrm{pA}(3 \mathrm{~mm})$ to $-19.1 \pm 2.7 \mathrm{pA}(6 \mathrm{~mm}),-15.1 \pm 1.5 \mathrm{pA}(9 \mathrm{~mm})$, and $-13.1 \pm$ $0.8 \mathrm{pA}$ (12 mm) (Fig. 2). This demonstrates that chronic (48 hr) depolarization can reduce mEPSC amplitude in the absence of ionotropic excitatory or inhibitory receptor activation.

Neurons treated with a high level of potassium and with ionotropic receptor blockade appeared healthy and showed no significant changes in resting membrane potential, input resistance, series resistance, or whole-cell capacitance when compared with control $(3 \mathrm{~mm})$ cells. Also, there was no consistent change in mEPSC kinetics (Fig. $2 B$ ) or in frequency between conditions (one-way ANOVA, $p \leq 0.88$, data not shown). This is in agreement with other studies that show that altering activity for $2 \mathrm{~d}$ does not significantly influence the placement or number of excitatory synapses onto pyramidal neurons (Micheva and Beau-

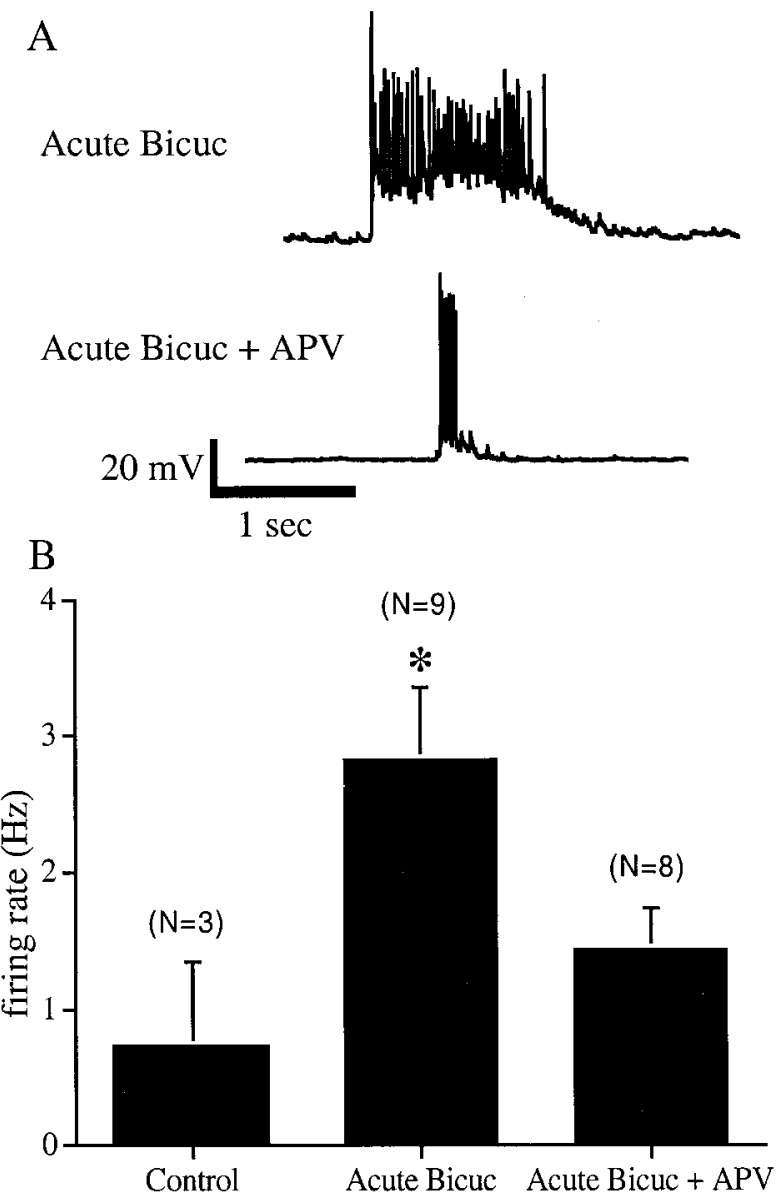

Figure 3. APV reduces firing rates in bicuculline-treated cultures. $A$, Representative recording from a neuron during acute application of ACSF containing bicuculline (Acute Bicuc), and after wash-in of bicuculline plus APV (Acute Bicuc $+A P V)$. B, Bicuculline enhances firing relative to controls ( $p \leq 0.03$ ), but firing rates are lower for bicuculline plus APV than for bicuculline alone $(p \leq 0.04)$. Cells were recorded at $35^{\circ} \mathrm{C}$ in ACSF containing $5.4 \mathrm{~mm} \mathrm{KCl}$. *Significantly different from controls, $p \leq 0.03$.

lieu, 1995) (V. Kilman and G. G. Turrigiano, unpublished observations).

\section{APV reduces firing rates in bicuculline}

We have shown previously that blocking NMDA receptor activation does not lead to an increase in quantal amplitude (Turrigiano et al., 1998). However, others have suggested that NMDA receptor activation is needed for the reduction in quantal amplitude produced by elevated activity, based on experiments showing that APV partially blocks the reduction in quantal amplitude induced by treatment with $\mathrm{GABA}_{\mathrm{A}}$ receptor antagonists (Lissin et al., 1998). An alternative explanation for this result is that blockade of NMDA receptors in the presence of $\mathrm{GABA}_{\mathrm{A}}$ receptor antagonists such as bicuculline results in lower firing rates and less depolarization overall than bicuculline alone. To test this hypothesis, we measured the firing rates of pyramidal neurons treated acutely with bicuculline $(20 \mu \mathrm{M})$ or bicuculline plus D-APV $(100 \mu \mathrm{M})$.

Acute application of bicuculline increased the firing rate of pyramidal neurons to $2.8 \pm 0.5 \mathrm{~Hz}$ compared with a firing rate of $0.7 \pm 0.6 \mathrm{~Hz}$ in controls $(p \leq 0.03)$. In addition neurons tended to fire in bursts of action potentials riding on top of a significant 


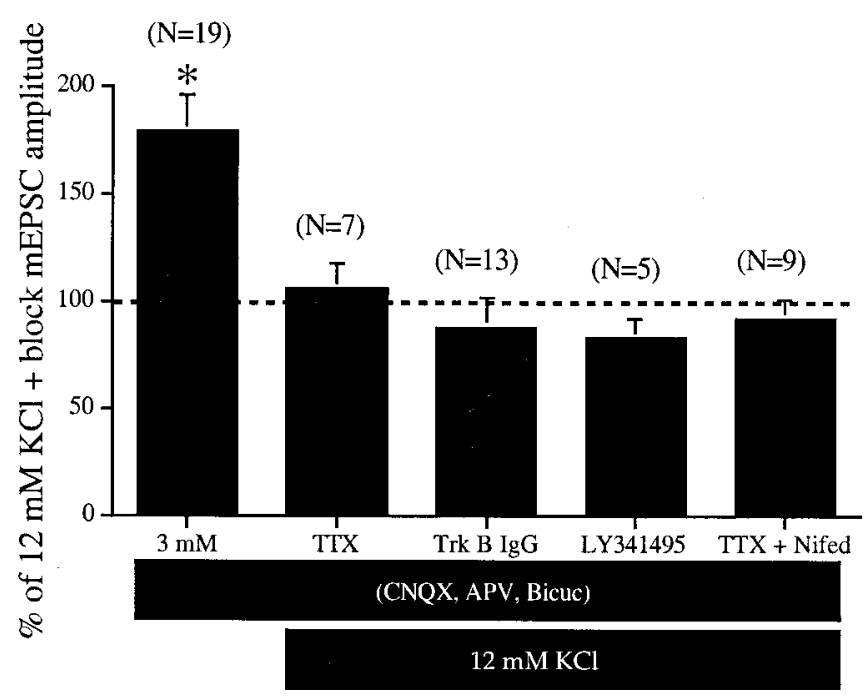

Figure 4. The reduction in mEPSC amplitude produced by $2 \mathrm{~d}$ of elevated $\mathrm{KCl}$ does not require action-potential firing, signaling through TrkB or mGluR receptors, or influx of calcium through L-type calcium channels. All cultures were grown for $2 \mathrm{~d}$ in ionotropic receptor blockade with $3 \mathrm{~mm} \mathrm{KCl}, 12 \mathrm{~mm} \mathrm{KCl}$, or $12 \mathrm{~mm} \mathrm{KCl}$ and the indicated pharmacological agent. All data are expressed as a percentage of the average mEPSC amplitude in $12 \mathrm{~mm} \mathrm{KCl}(100 \%)$ (dashed line). A $3 \mathrm{~mm}$ concentration of $\mathrm{KCl}$ is significantly larger than $12 \mathrm{~mm}(p<0.001)$, but none of the other conditions are significantly different from $12 \mathrm{~mm} \mathrm{KCl}$. *Significantly different from $12 \mathrm{~mm} \mathrm{KCl}$ and ionotropic receptor blockade.

level of depolarization (Fig. 3A). Neurons recorded in ACSF containing bicuculline and APV had an average firing rate of $1.4 \pm 0.3 \mathrm{~Hz}$, which was significantly lower than firing rates in bicuculline alone; in addition, the depolarizing envelope during the burst was significantly reduced ( $p \leq 0.04$ ) (Fig. 3). Most importantly, the firing rate in bicuculline and APV was not significantly higher than that in regular ACSF ( $p \leq 0.37, \mathrm{NS})$

\section{NMDA receptor activation does not promote scaling}

To assay directly for any role of NMDA receptor signaling in reducing mEPSC amplitudes, we treated cultures for $2 \mathrm{~d}$ with 12 $\mathrm{mM} \mathrm{KCl}$ in the presence of CNQX and bicuculline, with or without $100 \mu \mathrm{M} \mathrm{D}$-APV. If NMDA activation is important for synaptic scaling under these conditions, then we would expect an additional decrease in mEPSC amplitude with intact NMDA receptor signaling. No significant decrease was observed; instead, mEPSCs in the NMDA block condition were slightly smaller than those grown with NMDA signaling intact $(-12.5 \pm 1.0 \mathrm{pA}$ vs $-16.0 \pm 2.8 \mathrm{pA}$, respectively; NS, $p \leq 0.24$ ). Together with our previous results, these data suggest that NMDA receptor activation does not contribute significantly to the reduction in mEPSC amplitude produced by depolarization. The effects of APV seen by others can instead be explained by reduced overall depolarization in the bicuculline plus APV condition, as opposed to any direct role for NMDA receptor activation in synaptic scaling.

\section{Blocking spiking does not block the effect of depolarization}

A high level of $\mathrm{KCl}$ has two major effects: it depolarizes neurons and it increases firing rates. Are spikes needed to scale down mEPSC amplitude, or is depolarization enough? To test the relative contribution of action potentials to this regulation, we treated cells with $12 \mathrm{~mm} \mathrm{KCl}$ plus ionotropic receptor blockade, with or without $0.5 \mu \mathrm{M}$ TTX. Blocking action-potential genera- tion did not prevent the reduction in quantal amplitude produced by chronic depolarization (Fig. 4). In contrast, for sister cultures grown in control medium $(5.4 \mathrm{~mm} \mathrm{KCl})$ with synaptic transmission intact, $48 \mathrm{hr}$ of treatment with TTX increased mEPSC amplitude significantly $(250 \% \pm 30 \%$ of control values; $p \leq 0.01)$, as reported previously (Rutherford et al., 1998; Turrigiano et al., 1998; Watt et al., 2000). Hence, depolarization alone, in the absence of action-potential generation, is sufficient to induce a downregulation of mEPSC amplitude.

\section{Blocking TrkB signaling does not block the effect of depolarization}

BDNF can regulate quantal amplitude over part of the dynamic range (Rutherford et al., 1998). We reasoned that depolarization may result in the graded release of BDNF, causing a reduction in quantal amplitude at depolarized potentials. If this were the case, then blocking BDNF signaling under these conditions should block the reduction in quantal amplitude observed in the high potassium condition.

To explicitly test the role of BDNF in the depolarizationmediated regulation of mEPSC amplitude, we used a TrkB-IgG to scavenge extracellular BDNF and prevent activation of endogenous TrkB receptors. TrkB-IgG is a fusion protein of the extracellular domain of $\operatorname{TrkB}$, the high-affinity receptor for BDNF, and the Fc domain of human IgG (Shelton et al., 1995). To verify that the TrkB-IgG fusion protein was effective, we treated cultures grown in control medium $(5.4 \mathrm{~mm} \mathrm{KCl})$ without synaptic blockade with the TrkB-IgG for $2 \mathrm{~d}$ (at concentrations of 2 or $10 \mu \mathrm{g} / \mathrm{ml}$ ). As reported previously (Rutherford et al., 1998), this treatment increased mEPSC amplitude significantly $(173 \% \pm$ $21 \%$ of control values; $p \leq 0.002 ; 2$ and $10 \mu \mathrm{g} / \mathrm{ml}$ produced similar results so the data were combined). However, TrkB-IgG failed to block the decrease in mEPSC amplitude produced by chronic depolarization in ionotropic receptor blockade, either in the presence or in the absence of TTX (Fig. 4) (TrkB-IgG plus 12 $\mathrm{mm} \mathrm{KCl}$ was not significantly different from $12 \mathrm{~mm} \mathrm{KCl}$ alone; $p=0.4)$. This suggests that the reduction in quantal amplitude produced by depolarization is independent of TrkB signaling.

\section{Blocking mGluR signaling does not block the effect of depolarization}

It is possible that chronic depolarization of presynaptic terminals may release enough glutamate to activate metabotropic receptors, which might in turn reduce quantal amplitude. Metabotropic glutamate receptors have been shown to play a role in long-term depression (LTD) (Egger et al., 1999). If the reduction of quantal amplitude is indeed dependent on metabotropic receptor signaling (either presynaptic or postsynaptic), then blocking this signaling should prevent the decrease in quantal amplitude produced by elevated KCl. We used LY341495 (Bortolotto et al., 1999; Sawtell et al., 1999), a potent mGluR blocker (100 $\mu \mathrm{M})$, to test this hypothesis. LY341495 did not prevent the reduction in mEPSC amplitude produced by $12 \mathrm{~mm} \mathrm{KCl} \mathrm{(Fig.} \mathrm{4),} \mathrm{and} \mathrm{indeed,}$ there was a nonsignificant trend toward smaller quantal amplitudes in the presence of LY341495 (LY341495 plus $12 \mathrm{~mm} \mathrm{KCl}$ was not different from $12 \mathrm{~mm} \mathrm{KCl}$ alone; $p \leq 0.09$ ). Hence, metabotropic receptor activation is not needed for depolarization-induced scaling.

\section{Block of L-type calcium channels}

Chronic depolarization can downregulate quantal amplitude in a parametric manner, independently of BDNF and glutamate receptor activation. One obvious candidate for transducing mem- 
brane depolarization is the L-type VGCC. These VGCCs have been implicated in LTD (Cummings et al., 1996) and are themselves partially regulated by chronic changes in membrane potential (Franklin et al., 1992; Fickbohm and Willard, 1999).

We used nifedipine $(5 \mu \mathrm{M})$ to test the role of L-type VGCCs in this regulation. Nifedipine did not block the reduction in quantal amplitude induced by high levels of potassium in ionotropic receptor blockade with TTX (Fig. 4). This suggests that calcium influx through L-type VGCCs is not necessary for depolarization-mediated synaptic scaling.

\section{DISCUSSION}

We have shown that postsynaptic depolarization alone is sufficient to induce synaptic scaling in the absence of postsynaptic glutamate receptor signaling and action-potential generation. Although reducing BDNF activation of TrkB increases mEPSC amplitude under conditions of normal activity, here we find that postsynaptic depolarization reduces mEPSC amplitude in the absence of BDNF signaling. This suggests that both BDNF and depolarization cooperate to induce activity-dependent synaptic scaling over the entire dynamic range of quantal amplitudes.

Previous experiments have reported that postsynaptic glutamate receptor activation might be important for scaling. Both Turrigiano et al. (1998) and O'Brien et al. (1998) found that AMPA receptor blockade resulted in an increase in synaptic strength in cortical cultures and spinal cord cultures, respectively. Lissin et al. (1998) observed that NMDA receptor blockade partially blocked the effects of activity enhancement associated with $\mathrm{GABA}_{\mathrm{A}}$ receptor antagonists in hippocampal cultures. However, here we have shown that chronic depolarization can parametrically scale mEPSC amplitude over a large part of the dynamic range despite the complete blockade of ionotropically mediated synaptic transmission. This result suggests that the observed effects of glutamate receptor antagonists on synaptic scaling can be explained by overall changes in average membrane potential instead of by any direct effect of ionotropic receptor activation.

It is currently unclear how depolarization is transduced into an intracellular signal that scales down mEPSC amplitudes. We have ruled out an essential role for activation of ionotropic and metabotropic glutamate receptors, TrkB receptors, and L-type VGCCs. A number of other possibilities exist, including activation of other classes of VGCCs or depolarization-induced release of an unidentified factor. It is also possible that there are redundant mechanisms activated by depolarization, each of which can scale down mEPSC amplitude even in the absence of the other signals. Given the likely importance of synaptic scaling for network function, such redundancy would not be surprising but could make identification of the relevant intracellular signaling pathways difficult.

Keeping track of average depolarization would allow a neuron to track its own postsynaptic activity, which would be useful for stability rules such as synaptic normalization (Turrigiano and Nelson, 2000) as well as for the Bienenstock, Cooper, and Munro sliding plasticity-threshold rule (Bienenstock et al., 1982; Bear, 1995). Although spike counting might seem to be a useful measure of activity, it is a potentially ambiguous measure because low levels of depolarization (that are below threshold for spike generation) and saturating levels of depolarization (that inactivate sodium channels) both result in the same signal: no action potentials. In contrast, membrane potential provides a robust signal that always allows the neuron to regulate synaptic strengths in the proper direction. Regulation based on average membrane potential has the added advantage of integrating across spikes, bursts, and subthreshold activity.

BDNF is known to be an important activity signal for regulating synaptic scaling over part of the dynamic range of quantal amplitude. Although activity-dependent release of BDNF can account for many of the effects of activity, even relatively high concentrations of BDNF $(25 \mathrm{ng} / \mathrm{ml})$ are unable to reduce mEPSC amplitudes in pyramidal neurons to below control values (Rutherford et al., 1998). This suggests that there must be some other activity-dependent signal for reducing mEPSC amplitudes when activity rises. Our data suggest that postsynaptic depolarization provides this missing component.

If postsynaptic depolarization can track neuronal activity, then why should quantal amplitude also depend on BDNF? BDNF may act as a diffusible factor that allows neurons to communicate with their neighbors about local levels of activity. This is clearly the case with inhibitory interneurons, which do not produce BDNF but are responsive to it (Isackson et al., 1991; Zafra et al., 1991; Castren et al., 1992; Ghosh et al., 1994; Rutherford et al., 1997; Vicario-Abejon et al., 1998; Huang et al., 1999; Marty et al., 2000; Seil and Drake-Baumann, 2000). One advantage of a diffusible factor is that it can act at different sites within the network to balance both excitation and inhibition (Rutherford et al., 1998). Pyramidal neurons may also respond to the BDNF released by their neighbors. This would allow individual neurons to gauge local activity and regulate themselves accordingly, and may be important for the regulation of functional groups of neurons such as columns in the visual system. Our results suggest that BDNF and postsynaptic depolarization collaborate to scale mEPSC amplitudes over a large dynamic range. This may provide a robust mechanism for the homeostatic regulation of both unit and network level activity.

\section{REFERENCES}

Balkowiec A, Katz DM (2000) Activity-dependent release of endogenous brain-derived neurotrophic factor from primary sensory neurons detected by ELISA in situ. J Neurosci 20:7417-7423.

Bear MF (1995) Mechanism for a sliding synaptic modification threshold. Neuron 15:1-4.

Bienenstock EL, Cooper LN, Munro PW (1982) Theory for the development of neuron selectivity: orientation specificity and binocular interaction in visual cortex. J Neurosci 2:32-48.

Bortolotto ZA, Fitzjohn SM, Collingridge GL (1999) Roles of metabotropic glutamate receptors in LTP and LTD in the hippocampus. Curr Opin Neurobiol 9:299-304.

Castren E, Zafra F, Thoenen H, Lindholm D (1992) Light regulates expression of brain-derived neurotrophic factor mRNA in rat visual cortex. Proc Natl Acad Sci USA 89:9444-9448.

Cummings JA, Mulkey RM, Nicoll RA, Malenka RC (1996) $\mathrm{Ca}^{2+}$ signaling requirements for long-term depression in the hippocampus. Neuron 16:825-833.

Desai NS, Rutherford LC, Turrigiano GG (1999) BDNF regulates the intrinsic excitability of cortical neurons. Learn Mem 6:284-291.

Egger V, Feldmeyer D, Sakmann B (1999) Coincidence detection and changes of synaptic efficacy in spiny stellate neurons in rat barrel cortex. Nat Neurosci 2:1098-1105.

Fickbohm DJ, Willard AL (1999) Upregulation of calcium homeostatic mechanisms in chronically depolarized rat myenteric neurons. J Neurophysiol 81:2683-2695.

Franklin JL, Fickbohm DJ, Willard AL (1992) Long-term regulation of neuronal calcium currents by prolonged changes of membrane potential. J Neurosci 12:1726-1735.

Ghosh A, Carnahan J, Greenberg ME (1994) Requirement for BDNF in activity-dependent survival of cortical neurons. Science 263:1618-1623.

Huang ZJ, Kirkwood A, Pizzorusso T, Porciatti V, Morales B, Bear MF, Maffei L, Tonegawa S (1999) BDNF regulates the maturation of inhibition and the critical period of plasticity in mouse visual cortex. Cell 98:739-755.

Isackson PJ, Huntsman MM, Murray KD, Gall CM (1991) BDNF mRNA expression is increased in adult rat forebrain after limbic 
seizures: temporal patterns of induction distinct from NGF. Neuron 6:937-948.

Kokaia Z, Bengzon J, Metsis M, Kokaia M, Persson H, Lindvall O (1993) Coexpression of neurotrophins and their receptors in neurons of the central nervous system. Proc Natl Acad Sci USA 90:6711-6715.

Lissin DV, Gomperts SN, Carroll RC, Christine CW, Kalman D, Kitamura M, Hardy S, Nicoll RA, Malenka RC, von Zastrow M (1998) Activity differentially regulates the surface expression of synaptic AMPA and NMDA glutamate receptors. Proc Natl Acad Sci USA 95:7097-7102.

Marty S, Wehrle R, Sotelo C (2000) Neuronal activity and brain-derived neurotrophic factor regulate the density of inhibitory synapses in organotypic slice cultures of postnatal hippocampus. J Neurosci 20:8087-8095.

Micheva KD, Beaulieu C (1995) An anatomical substrate for experience-dependent plasticity of the rat barrel field cortex. Proc Natl Acad Sci USA 92:11834-11838.

Miranda RC, Sohrabji F, Toran-Allerand CD (1993) Neuronal colocalization of mRNAs for neurotrophins and their receptors in the developing central nervous system suggests a potential for autocrine interactions. Proc Natl Acad Sci USA 90:6439-6443.

O'Brien RJ, Kamboj S, Ehlers MD, Rosen KR, Fischbach GD, Huganir RL (1998) Activity-dependent modulation of synaptic AMPA receptor accumulation. Neuron 21:1067-1078.

Rae J, Cooper K, Gates P, Watsky M (1991) Low access resistance perforated patch recordings using amphotericin B. J Neurosci Methods 37:15-26.

Rutherford LC, DeWan A, Lauer HM, Turrigiano GG (1997) Brainderived neurotrophic factor mediates the activity-dependent regulation of inhibition in neocortical cultures. J Neurosci 17:4527-4535.

Rutherford LC, Nelson SB, Turrigiano GG (1998) BDNF has opposite effects on the quantal amplitude of pyramidal neuron and interneuron excitatory synapses. Neuron 21:521-530.

Sawtell NB, Huber KM, Roder JC, Bear MF (1999) Induction of NMDA receptor-dependent long-term depression in visual cortex does not require metabotropic glutamate receptors. J Neurophysiol 82:3594-3597.

Seil FJ, Drake-Baumann R (2000) TrkB receptor ligands promote activity-dependent inhibitory synaptogenesis. J Neurosci 20:5367-5373.

Shelton DL, Sutherland J, Gripp J, Camerato T, Armanini MP, Phillips HS, Carroll K, Spencer SD, Levinson AD (1995) Human trks: molecular cloning, tissue distribution, and expression of extracellular domain mmunoadhesins. J Neurosci 15:477-491.

Turrigiano GG (1999) Homeostatic plasticity in neuronal networks: the more things change, the more they stay the same. Trends Neurosci 22:221-227.

Turrigiano GG, Nelson SB (2000) Hebb and homeostasis in neuronal plasticity. Curr Opin Neurobiol 10:358-364.

Turrigiano GG, Leslie KR, Desai NS, Rutherford LC, Nelson SB (1998) Activity-dependent scaling of quantal amplitude in neocortical neurons. Nature 391:892-896.

Vicario-Abejon C, Collin C, McKay RD, Segal M (1998) Neurotrophins induce formation of functional excitatory and inhibitory synapses between cultured hippocampal neurons. J Neurosci 18:7256-7271.

Watt AJ, van Rossum MC, MacLeod KM, Nelson SB, Turrigiano GG (2000) Activity coregulates quantal AMPA and NMDA currents at neocortical synapses. Neuron 26:659-670.

Zafra F, Castren E, Thoenen H, Lindholm D (1991) Interplay between glutamate and $\gamma$-aminobutyric acid transmitter systems in the physiological regulation of brain-derived neurotrophic factor and nerve growth factor synthesis in hippocampal neurons. Proc Natl Acad Sci USA 88:10037-10041. 